Fritz Tödt

Elektrochemische Sauerstoffmessungen 



\title{
Elektrochemische Sauerstoffmessungen
}

\author{
Konzentrationsmessungen oxydierender und \\ reduzierender Stoffe durch galvanische Modellelemente \\ von \\ Fritz Tödt \\ Professor Dr.-Ing. habil., Oberregierungsrat an der Bundesanstalt \\ für Materialprüfung, Berlin-Dahlem \\ Mit einem Geleitwort von \\ Prof. Dr.-Ing. Max Pfender \\ Präsident der Bundesanstalt für Materialprüfung, Berlin-Dahlem
}

Mit 237 Abbildungen

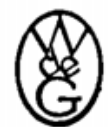

Walter de Gruyter \& Co., Berlin

vormals G. J.Göschen'sche Verlagshandlung · J. Guttentag, Verlagsbuchhandlung - Georg Reimer - Karl J. Trübner - Veit \& Comp. 
(C)

Copyright 1958 by Walter de Gruyter \& Co., vormals G. J. Gögchen'sche Verlagshandlung, J. Guttentag, Verlagsbuchhandlung, Georg Reimer, Karl J. Trübner, Veit \& Comp., Berlin - Alle Rechte, auch die des auszugsweisen Nachdrucks, der photomechanischen Wiedergabe, der Herstellung von Mikrofilmen und der Ubersetzung, vorbehalten - Printed in Germany - Archiv-Nr. 5211358 Satz: Walter de Grnyter \& Co.. Brrlin - Druck: Franz Spiller, Berlin 